\title{
Pre and Post Course Student Self Assessment of CeAB Graduate Attributes - A Tool for Outcomes Assessment, STUDENT SKILL AND COURSE IMPROVEMENT
}

\author{
Marnie V. Jamieson and John M. Shaw \\ Department of Chemical and Materials Engineering, Faculty of Engineering, University of Alberta \\ mvjamies@,ualberta.ca and jmshaw@ualberta.ca
}

\begin{abstract}
In addition to instructor assessment, capstone and introductory design students self-assess their skill levels based on their perceived attainment of and confidence in their ability to perform categorized skills related to the CEAB Graduate Assessment Attributes pre and post both courses. The assessment levels are no or introductory experience, developing, satisfactory and mastered. The goals of this initiative are to provide data for the CEAB mandated requirement for continuous course improvement, and to gauge student perceptions of their skill development as they progress through the design course sequence. The results from two sets of online surveys for each course have helped identify areas for course development and have helped prioritize course improvements in areas with the largest potential for attribute and skill improvement. Course delivery effectiveness was evaluated by comparison with previous cohorts, pre and post course student self-assessment, and student engagement and satisfaction survey data. This report focuses on the results of the pre and post course student self-assessments, including outcomes for cohorts completing all four surveys, and comparisons between students enrolled in the co-op program, who have an 8month gap between courses, and traditional engineering program students, who are younger on average and only have a one-month gap between courses.
\end{abstract}

Keywords: Engineering Accreditation, Student, Self, Outcomes, Course, Assessment, Graduate Attributes

\section{INTRODUCTION}

Self-assessment of common skills across courses provides an additional and frequently overlooked dimension to assessment and permits benchmarking relative to a common set of criteria across courses and years of study within an educational program. This type of assessment is particularly relevant in engineering because the assessment environment for programs of study is becoming increasingly proscriptive. This contribution also furthers the tradition of continual improvement in design course instruction (curriculum, teaching methodologies, and assessment) that has been practiced at the University of Alberta from the inception of the Chemical Engineering undergraduate program. With the establishment of web based teaching and learning methodologies, increased use of eLearning resources, and the facility of online monitoring, assessment, and data aggregation, the potential utility and desirability of including pre and post course student skill self-assessment related to the CEAB Graduate Assessment Attributes (CEAB GAA) in the mix of assessments is investigated.

\subsection{Motivation}

During a review of design course objectives, consideration was given to how the courses could demonstrate achievement of CEAB GA criteria. A pedagogical tool had previously been developed to assist students in self-selecting their teams with the objective of having skills required to be successful in the course represented on all teams. A plan to address gaps was required prior to team selection approval by the instructors. The student skill assessment form and the CEAB GAA were well aligned and the link to CEAB GAA was made explicit two years ago. For a team to be successful in the design course, the skills identified by instructors were typically found on the team - each individual did not have to be strong in every skill but the team needed to be strong in every skill area. This tool was redeveloped as part of an online individual skill assessment process that automatically compiled results into a proposed team composite skill profile. Students use this composite to assist in self-selection of team members, to create a development plan addressing skill gaps, to construct a team charter, and to assist in resourcing the design project schedule. Individual skills are classified according to the $\mathrm{CEAB}$ graduate attributes and the course objectives are linked to the attributes. The data are captured electronically to facilitate pre and post course result comparison for the two design courses individually and to track progress through both design courses. 
This automated on-line self-assessment tool was motivated by the design instructors' desire to create more balanced self-selected student design teams systematically. For design courses in particular, knowledge, skill and attribute categories linked with course objectives align fully with CEAB graduate attribute attainment. The desired outcome of the survey is for the strengths and weaknesses of individuals to be counterbalanced by the weaknesses and strengths of others on a team. Potential teammates are vetted, in part on the basis of the survey. The survey outcomes also underscore topics for focused development for individuals and for teams if a common area of weakness is identified. By administering the survey again at the end of the course student skill improvements can also be monitored. As the same survey is used in two design courses, attainment levels relative to the CEAB graduate attributes through the program can be demonstrated. The surveys also provide a feedback mechanism to course and program of study designers, for continual improvement of offerings vis-à-vis expected outcomes.

\subsection{Literature Review}

Performance measurement as a method of continual instructional improvement is a well-supported approach $[1-3,6]$. Content and process are inextricably linked [12]. How student learning is assessed impacts learning. This has led to changes in instructional/evaluation best practices over time that now include: cooperative work, writing focus, problem solving, real-world activities and de-emphasis of rote learning and teaching $[9,12]$. Linking assessment and instruction are a key principle for informing student progress and development [7]. In $\underline{A}$ Practical Guide to Alternative Assessment Joan Herman summarizes the active nature of learning in the context of research:

"Mere acquisition of knowledge and skills does not make people into competent thinkers or problem solvers. To know something is not just to passively receive information, but to interpret it and incorporate it; meaningful learning is reflective, constructive and selfregulated (Wittrock, 1991, Bransford and Vye, 1989, Marzano et al., 1988, Davis et al., 1990).” p. 15[7]

Herman makes it clear that learning is not a linear process, but rather a multifaceted contextual process that benefits from integrated assessment and real-world contexts.

\subsection{Problem Definition}

Currently, CEAB Graduate Attribute Assessment is based on instructor summative assessments related to the CEAB GAA in individual courses. Continuous course improvement is based on instructor analysis of universityadministered surveys for all courses. Automated skill self-assessment is seen as a method to measure CEAB GAA and to apply survey outcomes to improve the design courses as noted above without increasing instructor loading. Automation is particularly important, in light of enrolment growth from 125 students in 2015 to $\sim 200$ students by 2018 .

\subsection{Solutions Considered}

The student skill self-assessment was the only solution considered, as it was already in place in a manual format for team self-selection. Automation of this survey tool and making explicit use of the CEAB GA criteria for assessment is a logical step with multiple benefits (better equipped teams, better focus on learning needs, feedback to instructors and program of study developers, provision of an additional and complementary dimension to CEAB assessment). The tool was developed in such a way that it works seamlessly with the learning management system and can be customized for diverse courses or programs of study.

\subsection{Significance}

The work builds on what was formerly a manual paper based self-assessment process. The automated tool has since been adopted in courses where teams of students work together - using subject area pertinent criteria. The survey outcomes underscore topics for focused development for individuals and for teams if a common area of weakness is identified. As the same survey is used in two design courses, attainment levels relative to the CEAB graduate attributes through the program can be demonstrated. Systematic use of the same survey provides feedback to course and program of study designers, for continual improvement of offerings vis-à-vis expected outcomes. All of these benefits are achieved with no additional instructor loading.

\section{MEASURING CEAB Graduate Attribute ATTAINMENT USING ALIGNED ASSESSMENT}

\subsection{Linking course objectives to the CEAB GAA}

The CEAB GA for design is:

"An ability to design solutions for complex, openended engineering problems and to design systems, components or processes that meet specified needs with appropriate attention to health and safety risks, applicable standards, and economic, environmental, cultural and societal considerations. " [4]

Integrating course objectives and assessments with $\mathrm{CEAB}$ graduate attributes and their evaluation is a key objective. While there is a strong correlation between the 
capstone design course objectives and the CEAB GAA, the $\mathrm{CEAB}$ graduate attributes are a performance-based measurement of skill and experience (ability) attained and the course objectives are guidelines (a plan) for how success is achieved and demonstrated. Course objectives outline cognitive, affective, and intellectual development goals and are specifications for the design of the learning process required to produce the expected outcomes. Specifications for a process and performance measures of the product of the process (engineering education) should correlate, but they are not the same. The CEAB GAA performance measures provide targets but they do not define the paths to the targets. Aligned assessment support multiple paths that guide, support and test student learning.

\subsection{The CEAB Graduate Attributes as the Performance Based Assessment Measure}

The CEAB GAA is the performance measure that informs the contextual cognitive, affective, and intellectual development of engineering students throughout their undergraduate program. The opportunity for students to assess their progress towards these performance criteria continually is an integral part of the learning process [7]. The process used to produce graduates also benefits from the use of the CEAB GAA skill assessment. Just as student learning and development is inextricably linked to the method of assessment chosen, so are instructor, course and program performance. The chosen performance measure informs teaching practice.

Course and undergraduate engineering program design should allow opportunities for students to first learn and then demonstrate development of CEAB graduate attributes. Examinations are not the only or the best method for students to demonstrate their attainment of CEAB graduate attributes. It is also challenging for students to acquire and practice skills that demonstrate performance for the majority of the CEAB graduate attributes from a traditional lecture. For example, the "ability to work as an effective team member or leader" does not develop as a result of listening to a lecture on either topic [5]. It does not follow that knowledge of the principles of effective leadership makes someone an effective leader. In addition, changing only the method of assessment to one that allows for performance demonstration without providing the opportunity to develop the skill with feedback is equally ineffective. Performance-based assessment must inform course objectives and the design of teaching and learning objects that comprise a course.

\subsection{Linking Assessment to Content, Instruction, and Performance Criteria}

In a recent assessment meta study [6], the highest ranked factors for teaching or teacher related effects on student achievement are: formative feedback to teachers (.90), teacher clarity (.75), reciprocal teaching (.74), feedback (.73), spaced vs. mass practice (.71), metacognitive strategies (.69), self-verbalization/self questioning (.64), professional development (.62). All of these activities require instructor time and attention making them part of the instructor loading equation. By comparison the highest ranked factors for student controlled effects are: self report grades (1.44) and concentration persistence and engagement (.48) and gender (.12) [6]. Self-reporting of grades is a student prediction of how well they think they can do in the course prior to summative assessment. It would appear a student's only real recourse is institution and program choice to gain access to effective learning as most of the high impact effects fall directly in teacher and teaching realms. Instructors must have support from their institution to implement time-consuming, but high impact practices. Further, the time required to be effective at new course design and instructional techniques must be taken into account as instructors investigate and implement the techniques with the highest impact for the benefit of the overall program and for meeting CEAB GAA performance criteria in particular.

Classes with high enrolment are in direct opposition to the provision of quality feedback from instructors on multiple formative assignments. However, eliminating assessment linked to student development due to student numbers is to miss learning opportunities related to key objectives of the engineering program, especially the abilities to analyze, synthesize and evaluate contextual information. The development of meaningful learning opportunities to support skill development, and demonstration of performance are clearly linked $[1,12]$.

The integration of the CEAB performance objectives into the design of the course and allowing for students to use automated processes and tools to assess their own performance and that of their peers are valuable feedback mechanisms for student development. Students may use formative feedback during the course to improve both their processes and their performance. Formative assessment and developmental feedback are seen as critical aspects of course design. Student assessments and activities specific to learning objectives ensure that higher-level cognitive task skills and attribute performance development are guided.

\subsection{Course design and Assessment Framework}

A framework for course design and integrated CEAB graduate Attribute Assessment as the performance measure is illustrated in Figure 1. It is based on constructive alignment [1] and curriculum design processes [6]. The framework is intended to place course design in the broader context of overall undergraduate program curriculum design, CEAB performance based assessment of graduates and an integrated continual 


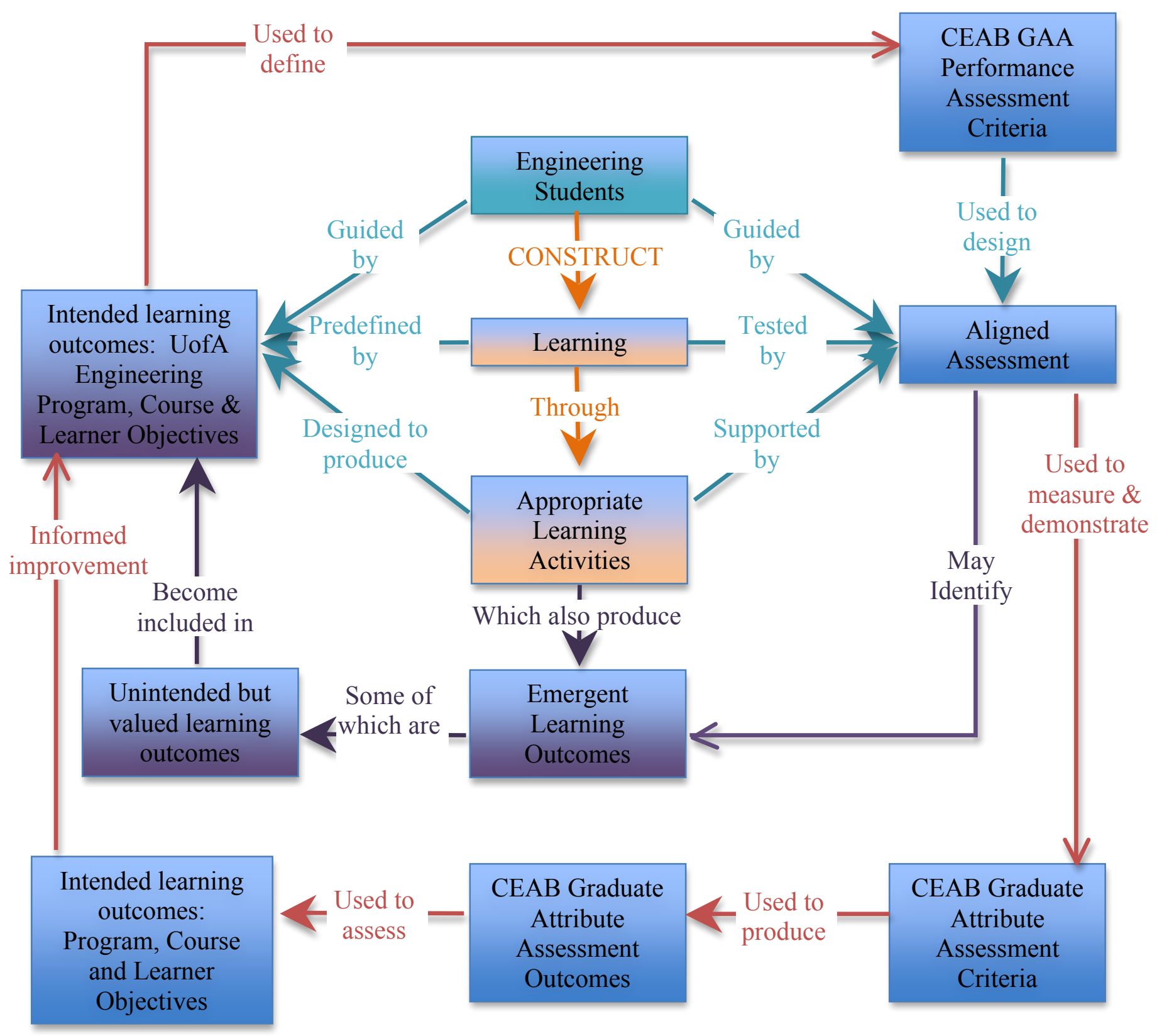

Figure 1. Continual improvement process algorithm for the University of Alberta Engineering Program Curriculum and Course Design Using CEAB GAA performance criteria based on a curriculum design process concept map (Hattie, 2009) illustrating constructive alignment (Biggs, 1996) as a core element and the feedback process of graduate performance measurement to inform program and course design (Jamieson 2015) -Adapted by MV Jamieson, 2015

improvement process. High stakes performance based assessment provides a means to assess higher order thinking skills and helps support students in developing a deeper understanding of content causing a shift in choice of instructional methods from teacher centered methods (lecture) to student centered methods including open response, problem solving, creative/critical thinking and inquiry based methods [13].

\section{EVALUATION METHOD}

A CEAB based skills and attributes self-assessment tool was developed to determine how students viewed themselves prior to and following the course. Data collection was automated and students made use of the pre-course assessments to select teams. Completion of 
the pre and post course self-assessment was mandatory for course completion. Just prior to the course, individual students self-assess their skills and abilities using the online CEAB GAA tool. Students are able to assemble a team and view their team composite skill and attribute data prior to finalizing their team selection. Their goal is to assemble a balanced team. The self-selected teams are accountable for ensuring they have the skills required, for establishing an agreed upon team structure, team values, performance and work quality norms. Students repeat the individual $\mathrm{CEAB}$ skill self-assessment at the end of the course. The composite data is used for course effectiveness evaluation, and inform CEAB GAA assessment. The post course self-assessment is completed prior to students receiving their final grade for the course.

\subsection{Level of Evaluation}

The CEAB graduate attribute for students regarding investigation suggests student cognitive development should reach a commitment level where knowledge is understood to be contextual. There is a right or wrong answer within a context:

"Investigation: An ability to conduct investigations of complex problems by methods that include appropriate experiments, analysis and interpretation of data, and synthesis of information in order to reach valid conclusions." [4] -emphasis mine

This investigation attribute is illustrative but a number of other attributes also appear to reflect this developmental milestone. The ability to reach valid conclusions, to design to meet specified needs, to understand limitations, understanding interactions and uncertainties predicting interactions between engineering solutions, economic, social, health, safety, legal, and cultural aspects of society all seem to require abilities outlined in the commitment stage [8]. As a Bachelor of Science in Chemical Engineering is the practicing degree and allows students to register as EITs with the professional association, the accreditation expectation that graduating students attain development described at Perry's commitment level $[10,11]$ is reasonable. The measurement of this development is somewhat reflected in the capstone design course final report. It is also reflected in the students' assessment and reflection of their progress as a team and their own assessment of their skills pre and post course.

\section{RESULTS AND DISCUSSION}

A positive self-assessment shift for students in the majority of skills and attributes surveyed was observed for both the introductory and capstone design courses. The pre-post course CEAB GAA progress is summarized in Table 1 for the 2015 capstone design cohort. For this cohort the largest positive shifts were noted in researching and investigating problems, design, team, report preparation, project management and accountability skill areas. Some areas such as use of engineering tools, error analysis, risk assessment and process control require further development and are the focus of ongoing course improvements. Figure 2 provides detailed information for CEAB GAA 4 (Design Complex Engineering Systems) for the 2015 capstone design course cohort and is illustrative of the data obtained for each attribute. Results for the 2016 iteration of the capstone design course, and the Fall 2015 introductory design course also indicate a positive shift in this attribute and the shift observed between the two courses is progressive.

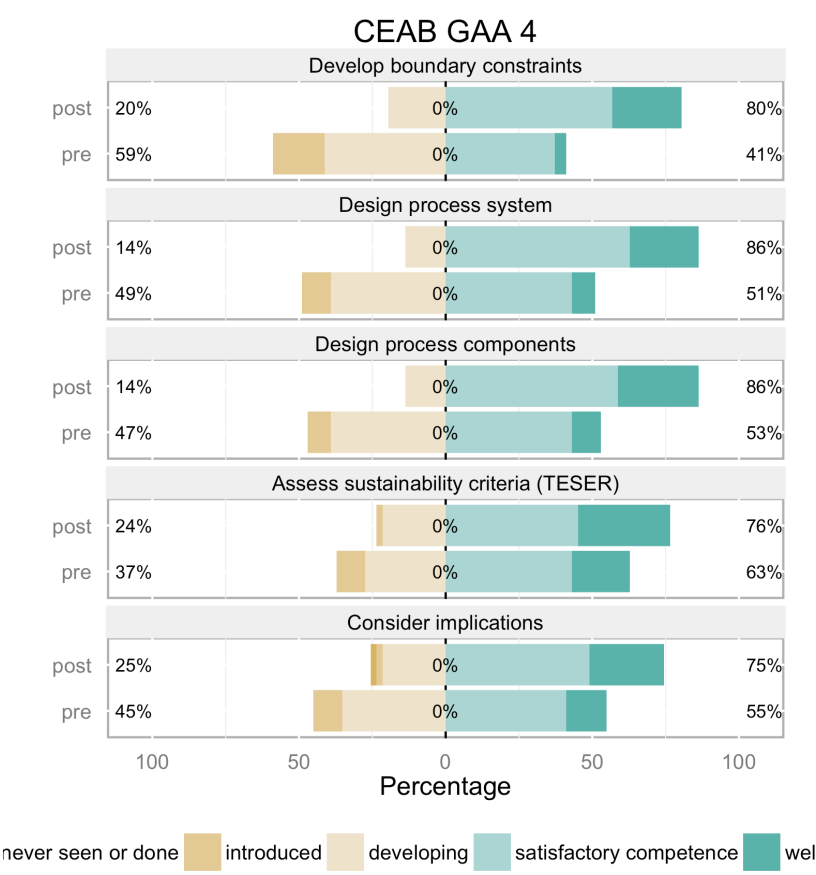

Figure 2. Capstone Design Course Pre - Post Likert Plot for the 2015 Cohort.

\subsection{Shifts Measured in CEAB GAA}

Some attributes and skills shifted significantly toward satisfactory competence and others less so. Some outcomes also correlated with instructor observations and have informed planned course improvements for the next iteration of the course. The self-assessment outcomes do not prove students have attained a certain level of competence in any of the attributes. They indicate where and to what extent students perceive they have developed. Student perceptions of their performance correlate with performance [6]. The exact nature or correspondence of 
students' perceptions and their actual skill level is variable. From the 2015 to 2016 cohorts several positive perceptions shifts were noted in the CEAB GAA for the following items: team, project management, impacts on society, especially risk assessment. These areas were targeted for course improvements between the iterations. Error Analysis and process control were not and no difference in the pre-post course survey shift was apparent for these topics.

Table 1: CEAB GAA Pre-Post Self-Assessment Summary for the 2015 Capstone Design Course Cohort.

\begin{tabular}{|c|c|c|}
\hline \multicolumn{3}{|c|}{$\begin{array}{c}\text { Pre-Post Course Graduate Attribute Shift } \\
\text { Introduced/Developing to Satisfactory/Well Developed. }\end{array}$} \\
\hline CEAB GAA & $\begin{array}{l}\text { Avg. } \\
\text { Shift }\end{array}$ & $\begin{array}{l}\text { \% Students } \\
\text { Satisfactory or Well } \\
\text { Developed }\end{array}$ \\
\hline $\begin{array}{l}\text { 1. Engineering } \\
\text { knowledge base }\end{array}$ & $\sim 10 \%$ & $\begin{array}{l}\sim 90 \% \text { (Weakest: } \\
\text { process control } \sim 60 \% \text { ) }\end{array}$ \\
\hline 2. Problem analysis & $\sim 20 \%$ & $\begin{array}{l}\sim 95 \% \text { (highest gain: } \\
\text { reach substantive } \\
\text { conclusions) }\end{array}$ \\
\hline 3. Investigation & $\sim 30 \%$ & $\begin{array}{l}\sim 90 \% \text { (weakest: error } \\
\text { analysis } \sim 70 \% \text { ) }\end{array}$ \\
\hline 4. Design & $\sim 30 \%$ & $\begin{array}{l}\sim 80 \% \text { (weakest: } \\
\text { consider implications } \\
\text { and assess } \\
\text { sustainability) }\end{array}$ \\
\hline $\begin{array}{l}\text { 5. Use of engineering } \\
\text { tools }\end{array}$ & $\sim 20 \%$ & $\begin{array}{l}75 \% \text { (weakest: } \\
\text { simulation software) }\end{array}$ \\
\hline $\begin{array}{l}\text { 6. Individual and } \\
\text { team work }\end{array}$ & $\sim 20 \%$ & $\begin{array}{l}90 \% \text { (weakest: } \\
\text { coaching \& learning } \\
\text { style) }\end{array}$ \\
\hline $\begin{array}{l}\text { 7. Communication } \\
\text { skills }\end{array}$ & $\sim 15 \%$ & $\begin{array}{l}\sim 90 \% \text { (highest gain: } \\
\text { report preparation) }\end{array}$ \\
\hline 8. Professionalism & $\sim 12 \%$ & $\sim 90 \%$ \\
\hline $\begin{array}{l}\text { 9. Impact of } \\
\text { engineering on } \\
\text { society and the } \\
\text { environment }\end{array}$ & $\sim 15 \%$ & $\begin{array}{l}\sim 70 \% \text { (weakest: } \\
\text { HAZOP) }\end{array}$ \\
\hline 10. Ethics and equity & $\sim 15 \%$ & $\begin{array}{l}90 \% \text { (highest gain } \\
\text { deviation } \\
\text { management) }\end{array}$ \\
\hline $\begin{array}{l}\text { 11. Economics and } \\
\text { project management }\end{array}$ & $\sim 20 \%$ & $\begin{array}{l}\sim 75 \% \text { For PM skills } \\
\text { higher for support } \\
\text { skills: planning, } \\
\text { communication, etc. } \\
\sim 80 \%\end{array}$ \\
\hline $\begin{array}{l}\text { 12. Life-long } \\
\text { learning }\end{array}$ & $\sim 12 \%$ & $\begin{array}{l}\text { } 90 \text { to } 95 \% \text { (weakest: } \\
\text { understand limitations } \\
\text { and meet self } \\
\text { education needs) }\end{array}$ \\
\hline
\end{tabular}

\subsection{Outcome Summary for Selected CEAB GAA for the 2015 Capstone Design Course Cohort}

4.1.1 A Knowledge Base for Engineering. The largest shifts from introduced/developing to proficient/mastered were seen in the areas of material selection $(25 \%)$ and process equipment $(20 \%)$. Shifts were $0-15 \%$ for most other topics with the exception of distillation (5\%), which coincidentally showed a high level of proficiency in the pre course results. Students typically indicated an increase in proficiency in all knowledge base categories.

4.1.2 Investigation. Investigation related skills were rated as developing by one third to over half of the respondents in the pre course survey. In the post course survey $85 \%$ to $90 \%$ of respondents rated themselves at the proficient or mastery levels for researching engineering problems, creating solution options, developing analysis criteria, synthesis of information and drawing valid conclusions. Only $71 \%$ indicated satisfactory competence or higher for error analysis - now a targeted topic for further enhancement - even though this skill showed significant improvement base on the difference between the pre to post course responses. Significant time was devoted to decision analysis, criteria formation and project application during in-class work. No in-class time or on line resources was devoted specifically to error analysis. Some time was spent on uncertainty impacts related to the fluid property and phase behaviour modelling and simulation. This topic will be enhanced and other examples developed for the subsequent iterations of the course.

4.1.3 Design Complex Engineering Systems. Figure 2 illustrates the student perception of development for specific design skills. The ability to develop boundary constraints shifted from $60 \%$ of students rating themselves at the introductory or developing stages to a $80 \%$ post course rating of satisfactory competence or mastered. Students' confidence in their ability to design a process system increased from $50 \%$ to $86 \%$, and their confidence in their ability to design process components increased similarly. Assessment of technical, economic, safety, environmental and risk components of the design increased by about $13 \%$ and consideration of implications increased by about $20 \%$.

4.1.4 Life-long Learning. The majority of students self assessed their competence related to life long learning skills as satisfactory or well developed in both the pre and post course surveys as shown in Figure 3. The ability to develop competence and the ability to identify selfeducational needs were rated as satisfactory or better by $96 \%$ and $92 \%$ of post course respondents. Some students were less confident in their ability to meet self-education needs and understand limitations.

\subsection{Differences in CEAB GAA between Co-op and Traditional Program Students}

The mean and distributions of self-assessed CEAB GA attainment levels for co-op and traditional program chemical engineering students were comparable for the introductory and capstone design course cohorts. This outcome had not been anticipated. The co-op students are 
one year older on average than the traditional students when the assessments are performed and the co-op students also possess a minimum of one year of engineering work experience. While this outcome was unanticipated, it is reinforced by student summative achievement. For example, in the capstone design course, co-op students are more likely to achieve a grade of $\mathrm{A}+$ than regular students, and regular students are more likely to achieve a grade of B- than co-op but the over all levels of achievement attained is comparable.

\section{CONCLUSIONS}

\subsection{Pre-Post Course Student Self-Assessment}

CEAB GAA development was demonstrated from the student perception data and correlated with the summative instructor assessment of the final report and indicated positive shifts for most CEAB GAA. The performance measures for the summative assessments of the situation and final reports are unchanged from previous years. Markers, marking and criteria remained the same and performance on average and on an individual basis maintained expectations.

Analysis of the introductory design course data demonstrates positive shifts that are contiguous with the shifts observed in the capstone design course.

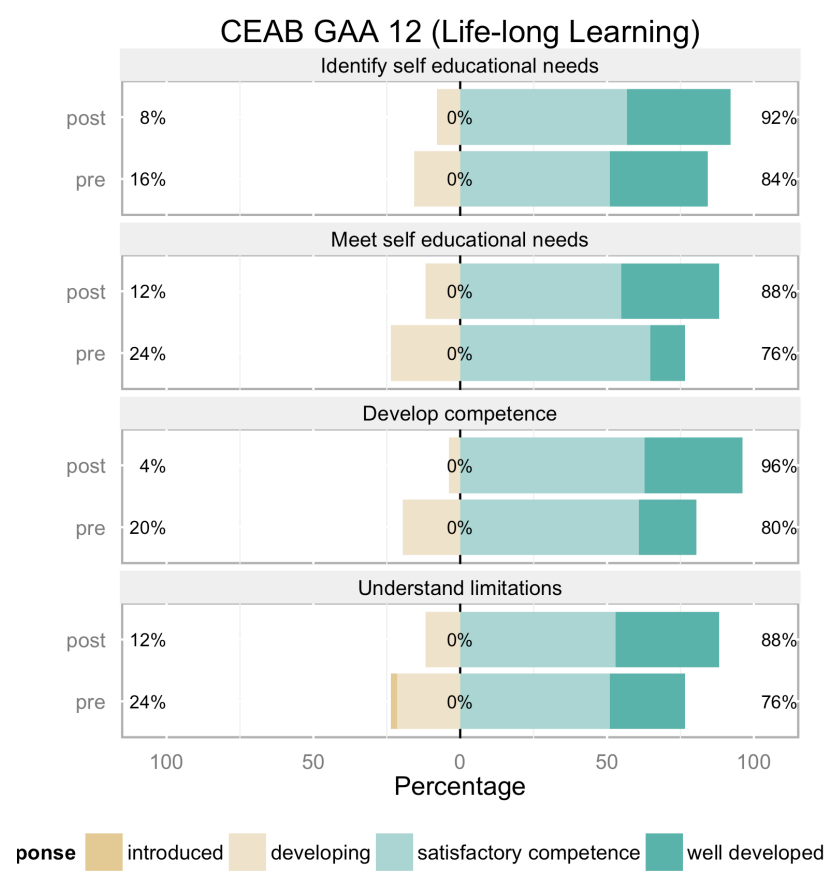

Figure 3. Life Long Learning Likert Plot Pre-Post Data

\subsection{Course Assessment Basis}

Development and revision of course materials for on line and in class use is time consuming. Pre-post comparative analysis of students' perception of their skills informed objective identification of course modules most in need of revision and supported continual improvement.

\section{Acknowledgements}

The design course redevelopment was funded by the Provost's Office (University of Alberta). The authors acknowledge with thanks the support given by Norma Nocente, Rishi Jaipaul and the CTL production staff, and the 2015 graduates of Chemical Engineering - Design Class.

\section{References}

[1] J.B. Biggs, What the Student Does: teaching for enhanced learning. Higher Education Research and Development, 18(1), 1999, pp 57-75.

[2] J.B. Biggs, Teaching for Quality Learning at University: What the Student Does. Buckingham; Philadelphia, PA: Society for Research into Higher Education : Open University Press, 2003.

[3] J.B. Biggs, C.S. Tang, \& Society for Research into Higher Education, Teaching for quality learning at university: What the Student Does, (Maidenhead, McGraw-Hill Education. 2011), 389pp. \{ISBN: 978-0335-22126-4\}.

[4] Canadian Engineering Accreditation Board, "Canadian Engineering Accreditation Board: Accreditation Criteria and Procedures", Ottawa: Canadian Council of Professional Engineers, 2014. Accessed June 20, 2015.

[5] E.L. Cussler, "Future of the Lecture". AIChE Journal DOI 10.1002/aic.14807, 2005

[6] J. Hattie, "The Black Box of Tertiary Assessment: An Impending Revolution", In L. H. Meyer, S. Davidson, H. Anderson, R. Fletcher, P.M. Johnston, \& M. Rees (Eds.), Tertiary Assessment \& Higher Education Student Outcomes: Policy, Practice \& Research (pp.259-275). Wellington, New Zealand: Ako Aotearoa, 2009

[7] J.L. Herman, A Practical Guide to Alternative Assessment. Alexandria, VA: Association for Supervision and Curriculum Development, 1992. \{ISBN: 0-87120-197-6\}

[8] Marnie V. Jamieson, “Application of Blended and Active Learning to Chemical Engineering Design Instruction", M.Sc. Thesis, University of Alberta, 2016

[9] D.M. Koretz, K. Mitchell, S.I. Barron, \& S. Keith, "The perceived effects of the Maryland School Performance 
Assessment Program: Final report" (CSE Technical Report No. 409). Los Angeles: University of California, Center for the Study of Evaluation, 1996.

[10] William G. Perry, Forms of Intellectual and Ethical Development in the College Years: a scheme, Holt, Reinhart and Winston, Inc. New York, 1970.

[11] W.J. Perry, Harvard Univ., C.C., \& And, O. "Patterns of Development in Thought and Values of Students in a Liberal Arts College: A Validation of a Scheme", Final Report. US Department of Education, 1968.
[12] L. Resnick, \& L. Klopfer, (Eds.) Toward the Thinking Curriculum: Current Cognitive Research, 1989. Alexandria, VA: Association for Supervision and Curriculum Development.

[13] K.E. Vogler, "The Impact of High-Stakes, State-Mandated Student Performance Assessment on Teachers' Instructional Practices", Education, 123(1), 39, 2002. 